\title{
A BOA-FÉ E O PROCESSO: O DEVER DE AGIR COM BOA-FÉ NO NOVO CÓDIGO DE PROCESSO CIVIL
}

GOOD FAITH AND THE PROCESS: THE DUTY TO ACT WITH GOOD FAITH IN THE NEW CIVIL PROCESS CODE

Boris Hermanson ${ }^{1}$

ISSUE DOI: $10.21207 / 1983.4225 .384$

\section{RESUMO}

Qual o significado do princípio da boa-fé processual previsto no Novo Código de Processo Civil? A quem este dever alcança? Quais as diferenças entre o que está previsto no Novo Código de Processo Civil e aquilo que estava previsto no Código de Processo Civil de 1973? Quais as condutas que revelam desrespeito ao princípio da boa-fé no Novo Código de Processo Civil? Quais as penalidades reservadas aos infratores dessa norma? Estas são as perguntas que se pretende ver respondidas neste artigo científico.

Palavras-chave: Princípio da boa-fé processual. Novo Código de Processo Civil. Condutas vedadas. Código de Processo Civil de 1973.

\section{ABSTRACT}

\footnotetext{
${ }^{1}$ Advogado especialista em Direito Processual Civil. Procurador Concursado do Município de Araras - SP. Atuando junto a Secretaria Municipal de Educação. Contato: hermansonboris@gmail.com.
} 
What is the principle of procedural good faith laid down in the New Code of Civil Procedure? Who is pervenit for this duty? What is the difference between what is foreseen in the New Code of Civil Procedure and what was provided for in the Civil Procedure Code 1973? What are the pipelines that reveal disrespect to the principle of good faith in the New Code of Civil Procedure? These are the questions that want to see answered in this scientific article.

Keywords: Principle of procedural good faith. New Civil Procedure Code. Prohibited conduct. Civil Procedure Code of 1973.

\section{INTRODUÇÃO}

O Código de Processo Civil de 1973 (Lei n . 5.869, de 11 de janeiro de 1973) repudiava condutas mal intencionadas por parte dos litigantes, não se permitindo às partes agirem da forma como melhor lhes aprovessem, contando que se vencesse a demanda, valendo-se dessa maneira da velha máxima de que os fins justificariam os meios.

Com o advento do Novo Código de Processo Civil (Lei $\mathrm{n}^{\circ}$. 13.105, de 16 de março de 2015), o legislador procurou não só manter a vedação à qualquer conduta que evidencie má-fé por parte dos litigantes, mas estendeu a aplicação de tal vedação aos demais participantes da relação processual, além de criar mecanismos mais eficientes para sua penalização.

Tendo em vista a infinidade de condutas que poderiam ser classificadas como má-fé processual, correndo-se o risco ainda de não conseguir exaurir todas suas hipóteses de ocorrência, o legislador preferiu, tanto no Código de Processo Civil de 1973 como no Novo, optar pela definição do que seja boa-fé, facilitando dessa forma ao julgador e às partes identificarem as situações que entrem em confronto com este princípio, sendo tais comportamentos taxados como demonstrativos da má-fé do agente que vier a praticá-lo.

Porém, para que se possa entender plenamente o instituto da boafé processual, é necessário inicialmente classificar suas modalidades, conforme o atual entendimento dos principais doutrinadores. 
Princípios representam normas gerais do Direito, os quais dão o direcionamento a ser seguido tanto pelo legislador como pelo operador do Direito. De acordo com Celso Antônio Bandeira de Mello, os princípios representam normas gerais do direito, mandamento nuclear de um sistema que irradia sobre diferentes normas compondo-lhes o espírito e servindo de critério para sua exata compreensão e inteligência. ${ }^{2}$

O princípio da boa-fé procesual é entendido pelo jurista Fredie Didier JR como uma norma de conduta processual que impõe e proibe condutas, criando também situações jurídicas ativas e passivas, ou seja, é retratado pelo Código de Processo Civil como boa-fé objetiva, a qual não se deve confundir com a boa-fé subjetiva contida na conduta íntima do agente da qual alguns fatos jurídicos dependem (DIDIER JR, 2015, p. 10. ${ }^{3}$

Dessa forma, pode-se afirmar que o princípio da boa-fé é uma norma que direciona a conduta do operador do Direito, fazendo-o agir com lealdade e com ética.

\section{A DIFERENÇA ENTRE BOA-FÉ SUBJETIVA E BOA-FÉ OBJETIVA}

Quando se fala em boa-fé é preciso saber conceituá-la sobre o aspecto subjetivo, isto é, o que se refere ao foro íntimo, às intenções do agente que age com boa-fé, daquela que é percebida através do respeito a preceitos que independem da vontade desse agente. Para ajudar nesta conceituação é importante entender as principais diferenças entre estas duas modalidades de boa-fé.

A boa-fé subjetiva é aquela presente em comportamentos regidos pela boa intenção, ou seja, refere-se a um estado psicológico do agente que age com ausência de más intenções.

Tendo em vista que a boa-fé subjetiva envolve verdadeira pesquisa quanto ao ânimo que moveu determinado agente, sua identificação torna-se muito difícil, sendo necessário realizar um verdadeiro processo

\footnotetext{
${ }^{2}$ MELLO, Celso Antonio Bandeira de. Curso de direito administrativo. 17 ed. São Paulo: Malheiros, 2004. p. 86.

${ }^{3}$ DIDIER JR., Fredie. Curso de Direito Processual Civil. V $1.17^{\circ}$ ed. Salvador: Editora JusPodivm, 2015. p. 104.
} 
investigativo para que seja formado um juízo de valor acerca de sua existência ou não num determinado caso concreto.

Neste sentido é que se afirma que a boa-fé não ultrapassa a esfera psicológica do ser, representando ela o conhecimento do bem, conforme Camila Gonçalves. ${ }^{4}$

Por outro lado, a boa-fé objetiva é verdadeira norma de conduta que independe da verificação quanto ao ânimo que motivou determinado agente, se ele agiu com boa intenção ou não. Dessa forma, sua existência ultrapassa o campo psicológico, adentrando no campo da ação, da conduta, que para revelá-la deverá espelhar um comportamento ético que demonstre que o agente esteja imbuído de honestidade suficiente para justificar uma mútua confiança.

No Novo Código de Processo Civil, em seu artigo $5^{\circ}$, a exemplo que já ocorria no Código de 1973, em seu artigo 14, o legislador estabeleceu que as partes têm o dever de agir com boa-fé, agindo assim com lealdade, probidade e veracidade.

Com a adoção dessas e de outras normas, em especial a que se encontrava prevista no artigo 129 do Código de Processo Civil de 1973 e agora no artigo 142 do Novo Código de Processo Civil, o legislador procurou agir de forma a evitar inclusive que as partes, em conluio, simulassem atos processuais ou o próprio processo com o intuito de violar a lei, procurando dessa forma, na visão de Vicenzi, evitar-se o dolo processual

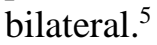

\section{AGENTES PROCESSUAIS AOS QUAIS SE APLICAM O PRINCÍPIO DA BOA-FÉ PROCESSUAL}

É dever de todos que participem de uma relação processual comportar-se de acordo com a boa-fé. Esta previsão, introduzida no artigo 14, inciso II, do Código de Processo Civil de 1973 e que consta na redação do artigo $5^{\circ}$ do Novo Código de Processo Civil, alcança não apenas as partes, mas também o orgão jurisdicional, incluindo Juízes, membros do Ministério Público, Defensores Públicos e os auxiliares da justiça.

\footnotetext{
${ }^{4}$ GONÇALVES, Camila de Jesus Mello, Princípio da Boa-fé - Respectivas e Aplicações. Rio de Janeiro: Elsevier, 2008. p. 28.

${ }^{5}$ VICENZI, Brunela vieira de. A boa-fé no processo civil. São Paulo: Atlas, 2003. p. 90.
} 
Até mesmo os sujeitos com particições apenas eventuais no processo devem se comportar com boa-fé objetiva. Isto alcança o curador especial, o corretor que participe da alienação de bem penhorado por iniciativa particular, o leiloeiro, o corretor de bolsa de valores, o mandatário, o administrador ou o gerente de ausentes, entre outros.

A BOA-FÉ NO CÓDIGO DE PROCESSO CIVIL DE 1973

O Código de Processo Civil de 1973 (Lei no 5.869, de 11 de janeiro de 1973) previa, numa série de artigos, a aplicação do princípio da boa-fé objetiva, proibindo e também penalizando as condutas que em tese revelariam a má-fé de uma das partes. Entre eles destacam-se os artigos 14, inciso II; 16. 17 e 18; 129; 273, inciso II; 538, parágrafo único; 557, parágrafo segundo; 600 e 601.

Entre os comportamentos que revelam a preocupação do legislador com a boa-fé processual objetiva, previstos no Código de Processo Civil de 1973 e que possuem tratamento similar previsto no Novo Código de Processo Civil, podemos citar o tratamento dispensado pelo legislador em relação às seguintes condutas: venire contra factum proprium, surrectio, supressio e o tu quoque.

\subsection{VENIRE CONTRA FACTUM PROPRIUM}

Pelo Código de 1973, era vedado a prática do venire contra factum proprium. Esta vedação se aplicava à prática de atos contraditórios realizados por uma mesma parte, conforme Menezes Cordeiro. ${ }^{6}$ De forma prática, pode-se dizer que temos através dessa conduta uma das partes aceitando uma determinada situação para depois questioná-la, inclusive na tentativa de imputar alguma nulidade processual pela sua prática.

Esta proibição podia ser encontrada no $\S 1^{\circ}$ do artigo 649 do Código de Processo Civil de 1973, que ao tratar das hipóteses de impenhorabilidade absoluta, determinava que tal condição não se aplicaria aos casos

${ }^{6}$ CORDEIRO, Antônio Menezes de. A boa-fé no direito civil. Lisboa, Almedina, 2007. p. 743. 
que envolvessem a cobrança do crédito concedido para a aquisição do referido bem impenhorável.

Outro caso em que o Código de Processo Civil de 1973 revelava ser inadmissível o comportamento contraditório da parte pode ser encontrado no inciso II do seu artigo 358, no qual temos a não aceitação, por parte do julgador, da recusa da parte em apresentar documento ao qual ela tiver se referido como prova na causa em discussão.

\subsection{SUPRESSIO}

Supressio significa a redução do conteúdo de determinada obrigação mediante o não exercício de um direito por seu detentor por determinado período de tempo, surgindo para a outra parte da relação jurídica a expectativa de que este direito não mais será exercido. Dessa forma, o detentor do direito, após a fruição do referido intervalo de tempo, não poderia mais exercê-lo validamente, pois isto violaria a boa-fé depositada pela parte contrária em que esta liberalidade fosse permamente, conforme se abstrai da lição de Duarte. ${ }^{7}$

O Código de Processo Civil de 1975, no $§ 2^{\circ}$ do seu artigo 685A, estabelecia a supressio do direito do cônjuge, descendente, ascendente do executado à adjudicação do bem penhorado que foi à hasta pública.

\subsection{SURRECTIO}

A surrectio serve para criar um direito em virtude do continuado comportamento de uma das partes, mesmo que este comportamento seja ilegal ou ainda viole disposição contratual. ${ }^{8}$

Neste sentido, os mesmos artigos que eram aplicáveis à vedação do venire contra factum proprium, a saber, $\S 1^{\circ}$ do artigo 649 e o inciso II do artigo 358, ambos do Código de Processo Civil de 1973, podiam ser

\footnotetext{
${ }^{7}$ DANTAS JUNIOR, Aldemiro Rezende. Teoria dos atos próprios no princípio da boafé. Curitiba: Juruá, 2007. p. 427.

${ }^{8}$ ROCHA apud MEZZOMO, Marcelo Colombelli. A boa-fé objetiva e seus institutos . Jus Navigandi, Teresina, ano 10, n. 1212, 26 out. 2006. Disponível em: . Acesso em: 29 set. 2010.
} 
utilizados como justificadores da aplicação do surrectio no processo civil, lembrando que o primeiro caso tratava das hipóteses de impenhorabilidade absoluta, determinando-se que tal condição não se aplicaria aos casos que envolvessem a cobrança do crédito concedido para a aquisição do referido bem impenhorável, e o segundo se referia à inadmissibilidade, por parte do julgador, da recusa da parte em apresentar documento ao qual ela tiver se referido como prova na causa em discussão.

\subsection{TU QUOQUE}

Tu quoque é a expressão latina que se refere à quebra de confiança que se dá em virtude do surgimento de um elemento surpresa. ${ }^{9}$

Esta regra representa a vedação do comportamento contraditório representado pela imposição de uma conduta não esperada pela outra parte, tal como era previsto pelo artigo 582 e seu parágrafo único do Código de Processo Civil de 1973 que vedava ao credor exigir o implemento da obrigação da outra parte antes que ele mesmo cumpra a sua obrigação.

De acordo com Menezes Cordeiro temos que

A ordem jurídica postula uma articulação de valores materiais, cuja prossecução pretende ver assegurados. Nesse sentido, ela não se satisfaz com arranjos formais, antes procurando a efectivação da substancialidade. Pois bem: a pessoa que viole uma situação jurídica perturba o equilíbrio material subjacente.

Nessas condições, exigir à contraparte um procedimento equivalente ao que se seguiria se nada tivesse acontecido corresponderia ao predomínio do formal: substancialmente, a situação está alterada, pelo que a conduta requerida já não poderá ser a mesma. Digamos que, da materialidade subjacente, se

\footnotetext{
${ }^{9}$ MEZZOMO, Marcelo Colombelli. A boa-fé objetiva e seus institutos . Jus Navigandi,
} Teresina, ano 10, n. 1212, 26 out. 2006. Disponível em: . Acesso em: 29 set. 2010. 
desprendem exigências ético jurídicas que ditam o comportamento dos envolvidos. ${ }^{10}$

\section{$5 \quad$ A BOA-FÉ NO NOVO CÓDIGO DE PROCESSO CIVIL}

O Novo Código de Processo Civil (Lei ${ }^{\circ}{ }^{\circ}$. 13.105, de 16 de março de 2015), tal como o Código de Processo Civil de 1973, também trata, em uma série de artigos, da aplicação do princípio da boa-fé objetiva, proibindo condutas que em tese revelem a má-fé de uma das partes que participem de uma relação processual.

No Capítulo I, Das Normas Fundamentais do Processo Civil, do Novo Código de Processo Civil, encontramos já em seu artigo $5^{\circ}$ que aquele que de qualquer forma participar do processo deve comporta-se de acordo com a boa-fé.

Este dispositivo constitui-se cláusula geral processual, conforme ensinamente do jurista Fredie Didier Jr. ${ }^{11}$

Existem também outras regras de proteção à boa-fé no Novo Codigo de Processo Civil, especialmente aquelas que estabelecem a punição para quem comportar-se com má-fé processual, elencando-se nestes dispositivos um rol exemplificativo contendo algumas das hipóteses que configuram má-fé processual.

Ainda, tal qual ocorria no Código de Processo Civil de 1973, o Novo manteve a vedação ao venire contra factum proprium, a exemplo do que encontramos em seu artigo 1.000, que trata da proibição da parte em recorrer de uma decisão que ela tenha aceitado, ou ainda em seu artigo 276 , ao impedir a decretação de nulidade nos casos em que ela for requerida pela parte que lhe deu causa.

Importante consignar que estes dois dispositivos servem também para justificar a aceitação, pelo Novo Código de Processo Civil, tanto do supressio como do surrectio. O primeiro por tratar-se da redução do conteúdo de determinada obrigação mediante o não exercício de um direito de seu detentor por determinado período de tempo, possibilita para a outra

\footnotetext{
${ }^{10}$ CORDEIRO, António Menezes. Litigância de má fé, abuso do direito de ação e culpa in agendo. Coimbra: Almedina, 2006. p. 115.

${ }^{11}$ DIDIER JR., Fredie. Curso de Direito Processual Civil. V 1. $17^{\circ}$ ed. Salvador: Editora JusPodivm, 2015. p. 104.
} 
parte da relação jurídica a expectativa de que este direito não mais será exercido, e o segundo por criar um direito em virtude do continuado comportamento de uma das partes, mesmo que este comportamento seja ilegal ou ainda viole disposição contratual.

Podemos encontrar exemplos de supressio e de surrectio respectivamente no artigo $876, \S 5^{\circ}$; artigo $833, \S 1^{\circ}$ e 399 , inciso II, todos do Novo Código de Processo Civil.

O Tu quoque também foi mantido no Novo Código de Processo Civil, que continua não permitindo o comportamento contraditório representado pela imposição de uma conduta não esperada pela outra parte, tal como previsto pelo artigo 787 em seu parágrafo único do Código de Processo Civil de 1973 que vedava ao credor exigir o implemento da obrigação da outra parte antes que ele mesmo cumprisse a sua obrigação.

Além desses, há no Novo Código, conforme a lição do jurista Fredie Didier Jr. (2015, pp. 110 - 113), a manutenção da proibição expressa de agir com má-fé, conforme expresso pelos artigos 258, 80 e 143, inciso I, todos do Novo Código de Processo Civil, bem como a proibição do abuso de direitos processuais prevista nos artigos 331, inciso I, 805 e 80, inciso VII, estes todos também do Novo Código de Processo Civil.

\section{PENALIDADES PREVISTAS PARA OS CASOS EM QUE HOUVER MÁ-FÉ}

O Novo Código de Processo Civil previu uma seção especialmente para tratar das penalidades aplicáveis àqueles que agirem com máfe processual. Ela está prevista na Seção II Da Responsabilidade das partes por Dano Processual, nos artigos de 79 a 81 do Novo Código de Processo Civil.

Conforme previsto no artigo 81, o juiz condenará o litigante de má-fé, de ofício ou de requerimento, a pagar multa superior a um por cento e inferior a dez por cento do valor corrigido da causa, indenizando também a parte contrária pelos prejuízos sofridos, arcando ainda com os honorários advocatícios e com todas as despesas que a parte contrária tiver suportado.

Entretanto, as penalidades não se esgotam neste tópico, antes, no artigos 77 e 78, do Novo Código de Processo Civil, especialmente no caso de descumprimento dos incisos IV e VI do artigo 77, porquanto foi estabelecido que agir com má-fé é considerado ato atentatório à dignidade da 
Justiça, tendo como penalidade, além das sanções criminais cabíveis, a aplicação de multa de até vinte por cento do valor da causa, multa esta que em não sendo paga será inscrita como divida ativa da União ou do Estado, podendo a parte infratora ser proibida de falar nos autos até a sua quitação, tudo conforme previsão contida nos parágrafos $2^{\circ}, 3^{\circ}$ e $7^{\circ}$ do referido artigo 77.

\section{CONSIDERAÇÕES FINAIS}

Espera-se que, com a aplicação correta e efetiva do princípio da boa-fé processual, finalmente haja o funcionamento correto e justo do Poder Judiciário.

Devemos lembrar que a boa-fé processual objetiva encontra-se intimamente ligada a vários direitos e garantias fundamentais, entre os quais detacam-se o do acesso à justiça, consagrado no artigo $5^{\circ}$, inciso XXXV da Constituição Federal, pelo qual se espera garantir a todos o direito de acesso a uma Justiça eficiente e justa, bem como ao princípio do devido processo legal, pelo qual se espera assegurar a efetivação das decisões proferidas pelos juízes e tribunais, através do devido processo legal e ao princípio da igualdade, visto que na má-fé a pessoa que age corretamente fica em posição de desigualdade perante a outra parte que age de forma indevida.

Dessa forma, aguarda-se que o advento do Novo Código de Processo Civil (Lei 13.105, de 16 de março de 2015), que alçou o princípio da boa-fé processual à categoria de norma fundamental do processo civil, represente efetivamente um grande avanço em relação ao Código de Processo Civil de 1973, e que esta medida por parte do legislador, conjugada com os princípios constitucionais com os quais ele se relaciona, deem à boa-fé processual uma envergadura muito maior do que a presenciada até hoje na vida dos operadores do Direito.

Outro ponto muito favorável que justifica uma mudança de expectativa se relaciona à ampliação das penalidades aplicáveis à má-fé processual, e ao reconhecimento de novas modalidades de condutas vedadas, entre elas a figura do abuso do direito processual, que somada a uma nova gama de soluções processuais jurídicas e extrajurídicas, entre as quais se destaca o estímulo às práticas de conciliação e mediação, à aplicação dos precedentes obrigatórios reduzindo-se as hipóteses em que uma demanda 
será analisada pelos tribunais superiores, bem como a redução das hipóteses de cabimento de determinados recursos, poderão resultar em mecanismos mais eficientes e céleres para a obtenção da Justiça, razão maior para a existência do Poder Judiciário.

Neste sentido, a boa-fé, refletida na colaboração processual entre as partes, desempenhará papel vital na mudança do paradigma atual de uma sociedade que prefere a judicialização de todo e qualquer conflito, de toda e qualquer demanda, para uma sociedade que prefira o diálogo para solucionar seus problemas.

Não obstante saber-se que onde houver conflito haverá interesses contraditórios e contrariados, o que por si só destimularia qualquer possibilidade de colaboração entre as partes, o fato que se traz à tona e que foi ressaltado no presente artigo é que a boa-fé que se pretende ver alcançada não é aquela subjetiva, que depende de fatores internos e psicológicos dos agentes que demandam e de seus representantes, mas antes, a boa-fé que produzirá os efeitos desejados é a objetiva, a positivada no presente ordenamento jurídico, em especial no Novo Código de Processo Civil, e cuja aplicação é resguardada pela punição pecuniária e pela restrição à possibilidade de defesa do infrator, fatores estes considerados suficientes para desestimular investidas contra este princípio processual fundamental.

Assim, ao depender menos das boas intenções dos agentes que atuem num processo e mais das regras que incentivem a utilização do espírito de colaboração entre as partes, penalizando aquelas condutas que evidenciem má-fé de quem quer que seja, o Novo Código de Processo Civil (Lei 13.105, de 16 de março de 2015), estará finalmente criando as condições necessárias para a mudança de paradigma tão perseguido por nossos juristas e por nossos juízes, a saber, a mudança de uma cultura na qual se incentiva a resolução de problemas através de sua judicialização para uma cultura que promova a conciliação e a adoção de métodos alternativos para a solução de conflitos.

No cenário que se desenha com as novidades apresentadas neste artigo, vislumbra-se uma mudança na realidade de quem depende, trabalha e atua junto ao Poder Judiciário Brasileiro, mudança que mesmo que venha a ocorrer de forma gradual espera-se que seja permamente.

\section{REFERÊNCIAS BIBLIOGRÁFICAS}


BATISTA, Silvio de Sá. Má-fé e Boa-fé na Processualidade Democrática. Rio de Janeiro: Editora Lumen Juris, 2015.

CORDEIRO, Antônio Menezes de. A boa-fé no direito civil. Lisboa, Almedina, 2007.

CORDEIRO, António Menezes. Litigância de má fé, abuso do direito de acção e culpa in agendo. Coimbra: Almedina, 2006.

DANTAS JUNIOR, Aldemiro Rezende. Teoria dos atos próprios no princípio da boa-fé. Curitiba: Juruá, 2007.

DIDIER JR., Fredie. Curso de Direito Processual Civil. V $1.17^{\circ}$ ed. Salvador: Editora JusPodivm, 2015.

. Curso de Direito Processual Civil. V 1. $9^{\circ}$ ed. Salvador: Editora JusPodivm, 2014.

DUARTE, Ronnie Preuss. Questões controvertidas no novo código civil. vol. 2. São Paulo: Método, 2004.

GONÇALVES, Camila de Jesus Mello, Princípio da Boa-fé Respectivas e Aplicações. Rio de Janeiro: Elsevier, 2008.

MELLO, Celso Antonio Bandeira de. Curso de direito administrativo. 17 ed. São Paulo: Malheiros, 2004.

MENDES, Débora Fernandes de Souza. A boa-fé como principio ideal do processo. Revista Âmbito Jurídico, Rio Grande do Norte. XV, $\mathrm{n}^{\mathrm{o}}$ 98, março 2012. Disponível em: HTTP://www.ambitojuridico.com.br/site/index.php?_link=revista_artigos-

leitura\&artigo-id=11246 Acesso em junho 2015.

MEZZOMO, Marcelo Colombelli. A boa-fé objetiva e seus institutos . Jus Navigandi, Teresina, ano 10, n. 1212, 26 out. 2006. Disponível em: . Acesso em: 29 set. 2010.

NEGREIROS, Teresa. Teoria do contrato - novos paradigmas. Rio de Janeiro: Renovar, 2002.

VIANA, Salomão; STOLZE, Pablo. Boa-fé objetiva processual: atual X novo CPC. Revista Jus Navigandi, Teresina, ano 17, n. 3326, 9 ago. 2012. Disponível em: <http://jus.com.br/artigos/22383> Acesso em 16 de junho de 2015.

VICENZI, Brunela vieira de. A boa-fé no processo civil. São Paulo: Atlas, 2003. 